\title{
Slc4a8 in the Kidney: Expression, Subcellular Localization and Role in Salt Reabsorption
}

\author{
Jie Xu Sharon Barone Kamyar Zahedi Marybeth Brooks Manoocher Soleimani \\ Center on Genetics of Transport and Epithelial Biology, Department of Medicine, University of \\ Cincinnati, Research Services, Veterans Affairs Medical Center, Cincinnati, USA
}

\section{Key Words}

Collecting duct $•$ Crispr/Cas9 $•$ Pendrin $\cdot$ Acid base regulation

\begin{abstract}
Background/Aims: The sodium-dependent bicarbonate transporter Slc4a8 (a.k.a NDCBE) mediates the co-transport of sodium and bicarbonate in exchange for chloride. It is abundantly detected in the brain, with low expression levels in the kidney. The cell distribution and subcellular localization of Slc4a8 in the kidney and its role in acid/base and electrolyte homeostasis has been the subject of conflicting reports. There are no conclusive localization or functional studies to pinpoint the location and demonstrate the function of Slc4a8 in the kidney. Methods: Molecular techniques, including RT-PCR and in situ hybridization, were performed on kidney sections and tagged epitopes were used to examine the membrane targeting of Slc4a8 in polarized kidney cells. Crispr/Cas9 was used to generate and examine Slc4a8 KO mice. Results: Zonal distribution and in situ hybridization studies showed very little expression for Slc4a8 (NDCBE) in the cortex or in cortical collecting ducts (CCD). Slc4a8 was predominantly detected in the outer and inner medullary collecting ducts (OMCD and IMCD), and was targeted to the basolateral membrane of osmotically tolerant MDCK cells. Slc4a8 KO mice did not show any abnormal salt or bicarbonate wasting under baseline conditions or in response to bicarbonate loading, salt restriction or furosemide-induced diuresis. Conclusion: Slc4a8 (NDCBE) is absent in the CCD and is predominantly localized on the basolateral membrane of medullary collecting duct cells. Further, Slc4a8 deletion does not cause significant acid base or electrolyte abnormalities in pathophysiologic states. Additional studies are needed to examine the role of Slc4a8 (NDCBE) in intracellular $\mathrm{pH}$ and volume regulation in medullary collecting duct cells.




\section{Cellular Physiology Cell Physiol Biochem 2018;50:1361-1375 \begin{tabular}{l|l|l} 
DOI: 10.1159/000494596 & O) 2018 The Author(s). Published by S. Karger AG, Basel \\
www.karger.com/cpb
\end{tabular} \\ Xu et al.: Slc4a8 in the Kidney}

\section{Introduction}

Systemic vascular volume regulation and acid-base homeostasis are accomplished through the reabsorption of filtered salt $(\mathrm{NaCl})$ and secretion of acid or base equivalents in various nephron segments [1-28]. The bulk of salt reabsorption occurs in the proximal tubule [1-9] followed by the thick ascending limb of Henle [10-11] and the distal convoluted tubule (DCT) [12-14]. The collecting duct (CD) and the connecting tubule (CNT); however, play a critical role in electrolyte and acid base homeostasis by fine tuning the $\mathrm{H}^{+}$and $\mathrm{HCO}_{3}{ }^{-}$ transport and electrolyte composition of urine [15-23]. The sodium absorption in the CNT and cortical collecting duct (CCD) is predominantly mediated via the epithelial sodium channel, $\mathrm{ENaC}$, in principal cells; whereas, chloride is absorbed via both transcellular and paracellular pathways [24-28].

The transcellular absorption of chloride in CNT and CCD is primarily mediated via pendrin, an apical $\mathrm{Cl}^{-} / \mathrm{HCO}_{3}^{-}$exchanger expressed in non A-intercalated cells and designated as SLC26A4 [16-20; 29-34]. Mice with the genetic deletion of pendrin or humans with inactivating mutations of the pendrin gene do not display excessive salt and fluid wasting or altered blood pressure under baseline conditions [33, 34]. Recent studies demonstrate that the $\mathrm{Na}-\mathrm{Cl}$ cotransporter $\mathrm{NCC}$ (Slc12a3) and the $\mathrm{Cl}^{-} / \mathrm{HCO}_{3}{ }^{-}$exchanger pendrin (Slc26a4) crosscompensate for each other's loss of function, hence mitigating the magnitude of salt wasting in response to the inactivation/down-regulation of NCC or pendrin [35-38].

The SLC4A8 is a sodium-dependent bicarbonate transporter which was cloned based on homology to other NBCs, including SLC4A4 (a.k.a NBCe1; a.k.a. NBC1) [39-41]. It was originally given the designation of $\mathrm{NBC}-3[39,40]$ and subsequently renamed as NDCBE, consistent with functioning as a sodium-dependent $\mathrm{Cl}^{-} / \mathrm{HCO}_{3}{ }^{-}$exchanger [41]. In mice, Slc4a8 is abundantly detected in the brain, with very low expression levels in the kidney $[39,40,42$, $43,44]$.

Original studies on Slc4a8 (a.k.a NBC-3) in the kidney showed predominant expression in the medulla with low or no expression in the kidney cortex, and that it was sensitive to inhibition by stilbene DIDS in Oocytes $[39,40]$. A more recent study reported a HCTZ (hydrochlorothiazide)-sensitive salt absorptive pathway in the CCDs of sodium-depleted mice that was attributed to Slc4a8 [45]. The authors proposed that Slc4a8 is located on the apical membrane of B-intercalated cells and collaborates with pendrin to facilitate the reabsorption of sodium and chloride in the collecting duct [45]. No localization studies (such as RT-PCR, immunohistochemical labeling and/or in situ hybridization) were utilized to demonstrate the localization of Slc4a8 in cortical collecting duct or, more specifically, in B-intercalated cells, and no functional studies were performed to directly pinpoint the location or demonstrate the function of Slc4a8 in the kidney. A follow up study comparing Slc4a8/NCC double KO mice vs. single NCC KO mice suggested that Slc4a8 may prevent the generation of hypokalemia in NCC KO mice by working in tandem with pendrin to claim the luminal salt in an ENaC-independent manner [46].

To gain better insight into the cellular distribution, membrane targeting, and role of Slc4a8 (NDCBE) in the kidney, we performed a series of studies, including in situ hybridizations, membrane targeting in polarized kidney collecting duct cells, and generation and examination of Slc4a8 null mice. Our results demonstrate that Slc4a8 is completely absent in the cortex, including the CCD, and is primarily detected in medullary collecting duct cells. Slc4a8 null mice do not demonstrate any phenotypic salt wasting or acid base dysregulation in response to bicarbonate loading, salt restriction or furosemide-induced diuresis. 


\section{Cellular Physiology Cell Physiol Biochem 2018;50:1361-1375 and Biochemistry Published \begin{tabular}{l|l} 
DOI: 10.1159/000494596 & $\begin{array}{l}\text { c } 2018 \text { The Author(s). Published by S. Karger AG, Basel } \\
\text { www.karger.com/cpb }\end{array}$
\end{tabular} Xu et al.: Slc4a8 in the Kidney}

\section{Materials and Methods}

\section{Expression of Slc4a8 in the kidney by RT-PCR}

Mouse Slc4a8 has two distinct variants, with Variant 1 (gene accession number: NM_021530.2) being longer than variant 2 (gene accession number: NM_001347102.1) by 225 nucleotides and showing $50 \%$ homology within the next 83 nucleotides with Variant 2. The rest of the DNA sequence, which spans more than 11, $200 \mathrm{bp}$, is identical between the two variants. To examine the expression of Slc4a8 in mouse kidney, the following primers which are common to both variants were designed using the mouse Slc4a8 cDNA sequence (Genbank Accession number: NM_021530): ATCGGCACCACCGCACTCAT (sense) and AGCAGGGCTTCCCGCACTTT (antisense). The cycling parameters were $94^{\circ} \mathrm{C}$ for $1 \mathrm{~min}$, then 35 cycles at $94^{\circ} \mathrm{C}$ for $30 \mathrm{~s}$, and $68^{\circ} \mathrm{C}$ for $1 \mathrm{mi}$. As indicated, the above DNA fragment encodes a sequence common to both variants of Slc4a8 (variants 1 and 2). The primers GCAGCTGTGCAAGGTGGATG (sense, specific for variant 2) and AGCAGGGCTTCCCGCACTTT (antisense) are specific for the N-terminal end of the shorter variant 2 (Genbank accession number: NM_001347102). The primers for the N-terminal end of slc4a8 variant 1 (gene bank accession number: nm_021530) are TCGCGGGCTGATGGCTATGAA(sense) and TTGTGCTGGTCCCACCC TGA(antisense).

The above primer pairs were used for RT-PCR on mouse kidney RNA isolated from cortex, outer medulla and inner medulla.

\section{Expression of Slc4a8 by in situ hybridization}

The PCR product of mouse Slc4a8 cDNA fragment, encoded by the primers ATCGGCACCACCGCACTCAT (sense) and AGCAGGGCTTCCCGCACTTT (antisense), was purified and ligated into a pGEM-T Easy Vector (Promega, Madison, WI). The plasmid was linearized using SacII and BstXI restriction enzymes for antisense and sense cRNA synthesizing, respectively. The antisense and sense cRNA probes were synthesized using DIG RNA Labeling Kit (SP6/T7) (Sigma Aldrich, St. Louis, MO). In situ hybridization experiments were performed on normal mouse brain and kidney sections using a in situ hybridization kit (Biochain, Newark, CA). Briefly, the paraffin slides were deparaffinized and rehydrated, fixed with $4 \%$ paraformaldehyde, treated with $10 \mathrm{ug} / \mathrm{ml}$ proteinase $\mathrm{K} 15$ minutes, subjected to pre-hybridization solution for 4 hours at $50^{\circ} \mathrm{C}$, followed by treatment in hybridization solution with antisense or sense probe $(3 \mathrm{ng} / \mathrm{ul})$ overnight at $55^{\circ} \mathrm{C}$. Slides were washed with $2 \mathrm{x}, 1.5 \mathrm{x}$ and $0.2 \mathrm{x}$ SSC buffer, incubated with blocking solution for 1 hour at room temperature, incubated with 1:250 AP-conjugated anti-digoxingenin antibody over night at $4^{\circ} \mathrm{C}$, followed by NBT/BCIP incubation for 12 hours.

\section{Cloning the full-length mouse Slc4a8}

Full-length mouse Slc4a8 cDNA (long variant) was amplified from mouse kidney medulla RNA using the following PCR primers: 5'-TGGAACCTACCGGCGAGACC (sense) and 5'-TCCCGGAGAGACTCGCCATTT (antisense). These primers encode nucleotides 149 to 3537 of mouse Slc4a8 cDNA (GenBank accession number: NM_021530) and contain the entire open-reading frame. Amplification of mouse Slc4a8 cDNA by PCR was performed according to the Clontech Advantage-HF 2 PCR kit protocol (Clontech, Mountain View, CA). The PCR product was cloned into the GFP fusion TOPO vector (pcDNA3.1/NT-GFP-TOPO vector, Cat number:k481001). This resulted in the expression of GFP-tagged Slc4a8 protein with the GFP fusing to the N-terminus of Slc4a8. In parallel studies, the PCR product was ligated into the mammalian expression pTarget Vector (Promega, Madison, WI) for expression studies.

\section{Cell culture and transfection procedures}

For transient transfection studies, MDCK (Madin-Darby Canine Kidney) from ATCC (CRL 2936), were seeded on coverslips in a 24 wells plate $24-48 \mathrm{hrs}$ before transfection, and were transfected at 7090\% confluence with $0.8 \mu \mathrm{g}$ of full-length Slc4a8 cDNA construct by Lipofectamine 3000 (Thermo Fisher Scientific, Waltham, MA). Both GFP-tagged as well as a non tagged Slc4a8 full length cDNA were used. Twenty four (24) hrs after transfection, the medium was changed, with one group kept in normal medium and one group switched to a hypertonic medium (with $50 \mathrm{mmol} / \mathrm{l} \mathrm{NaCl}$ ) for incubation overnight. Cells were examined $48 \mathrm{~h}$ after transfection. The experiments for each maneuver were repeated at least 6 times. 


\section{Cellular Physiology Cell Physiol Biochem 2018;50:1361-1375

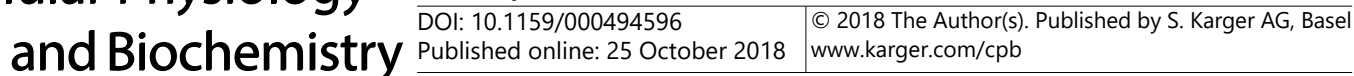 \\ Xu et al.: Slc4a8 in the Kidney}

\section{Confocal microscopic examination of Slc4a8}

Transfected cells were washed and fixed in $4 \%$ formaldehyde-PBS solution as described $[47,48]$. For co-labeling studies, MDCK cells were permeabilized with $0.1 \%$ Triton X-100 in PBS for 15 minutes. Two different set of studies were performed. In one set, the Slc4a8-GFP construct was used for transfection in MDCK cells. In separate studies, a non GFP Slc4a8 construct was used to transfect MDCK cells which were incubated with mouse anti-NDCBE antibodies (1:100) (Santa Cruz Biotechnology, Dallas, TX) at $4^{\circ} \mathrm{C}$ overnight. Cells were switched to either a hypertonic medium or remained in isotonic medium $24 \mathrm{hrs} \mathrm{later}$ and fixed $48 \mathrm{~h}$ after transfection. All cells were co-labeled with Alexa Fluor 568 phalloidin (Molecular Probes, Eugene, OR) as a marker of apical membrane labeling. Images were taken on a Zeiss LSM710 confocal microscope. Both Z-line and Z-stack images were obtained using the LSM 5 Image software to analyze the membrane expression of Slc4a8 [47, 48]. All samples were repeated in triplicate for each experiment, and each experiment was repeated three independent times.

\section{Generation of Slc4a8 KO mice by CRISPR/CAS9}

Strategy. In order to knock out the Slc4a8 gene using the CRISPR system, two gRNAs that target the coding sequence of exon 3 and exon 4, respectively, were designed and injected along with Cas 9 mRNA into cell embryos derived from mice of C57 background. The injections were performed at the Mouse Genome Facility, Children Hospital, University of Cincinnati.

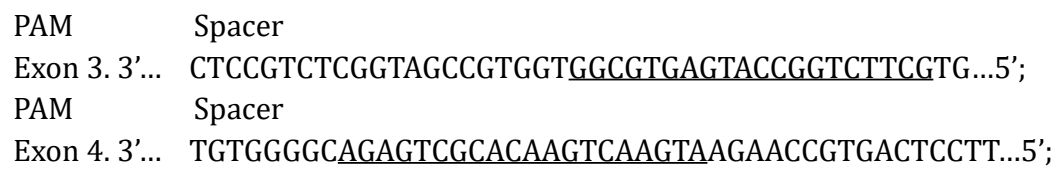

Results. We obtained 27 mice (\#8771-8798) from the gRNA injections. We ran PCR on individual target sites. For target site in exon 3, there were at least 15 mice showing editing. The PCR products were sequenced which showed two mice (M8772 and M8787) had relatively large deletions (see genotyping pictures in Supplementary Fig. S1A - for all supplementary material see www.karger.com/10.1159/00049459/). For mouse M8772, $40 \mathrm{bp}$ in exon 3 deletion is highlighted below:

\section{acacccttttgtggaaggaattctctctgagtcttctgcttccatccagGTCATAGAACTCTG TATGTGGGGGTTCGGATGCCGCTGGGGAGGCAGAGCCATCGGCACCACC GACTCATGGCEAGAAGCACCGGAGACGAGGAGGGCGGGGCAAAGGAGCC AGCCAGGGCGAGGAGGGCTTGGAAGCCTTGGCCCACGgtaac}

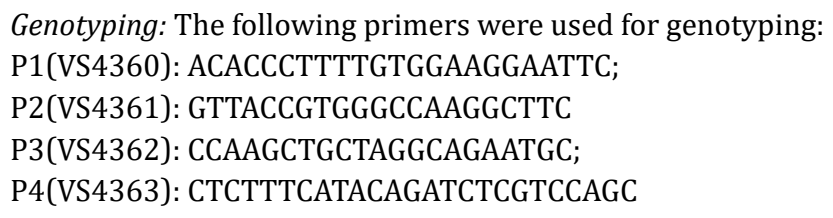

Primers P1 and P2 were used for amplifying exon 3, with an amplicon of 204 bp (WT). Primers P3 and P4 were used for exon 4, with an amplicon of $190 \mathrm{bp}$ (WT). Primers 1 and 4 can be used to amplify the region across exons 3 and 4, with an amplicon of 993 bp (WT). Founder M8772 was crossed with wild type mice and the resulting heterozygote offspring were crossed to generate Slc4a8 KO mice (Supplementary Fig. S1B). The Slc4a8 KO mice are viable and grow normally.

Animal husbandry and experiments. Mice were cared for in accordance with protocols approved by the Institutional Animal Care and Use Committee (IACUC) at the University of Cincinnati and the VA Hospital. All animal handlers are IACUC trained. Animals had access to food and water ad libitum (unless subjected to a specific protocol), were housed in humidity-, temperature-, and light/dark-controlled rooms, and were inspected daily. Animals were euthanized with the use of excess anesthetics $(0.150 \mathrm{ml}$ euthazol per mouse) according to institutional guidelines and approved protocols.

Mice (WT: 5 animals: 3 males/2females or KO: 5 animals: 3 males/2 females) were placed in metabolic cages and after acclimation and were subjected to either bicarbonate loading for 4 days $\left(140 \mathrm{mM} \mathrm{NaHCO}_{3}\right.$ 


\section{Cellular Physiology Cell Physiol Biochem 2018;50:1361-1375 \begin{tabular}{ll|l} 
DOl: 10.1159/000494596 & $\begin{array}{l}\text { O 2018 The Author(s). Published by S. Karger AG, Basel } \\
\text { www.karger.com/cpb }\end{array}$ \\
\hline
\end{tabular} \\ Xu et al.: Slc4a8 in the Kidney}

added to the drinking water), salt restriction $(0.1 \% \mathrm{NaCl}$ diet $)$ for 6 days, or furosemide-induced diuresis $(30 \mathrm{mg} / \mathrm{kg}$ furosemide given ip once a day for 3 days). Five (5) animals placed in metabolic cages for the same duration were used as baseline. Urine $\mathrm{pH}$ and electrolyte excretion rate as well as serum electrolytes and acid base status were determined as described [37]. For dehydration, mice were subjected to water deprivation for $24 \mathrm{hrs}$ with free access to food. This maneuver is associated with increased urine osmolality and enhanced medullary tonicity [49]. Four animals were subjected to water deprivation and compared to control group ( $\mathrm{n}=4$ per each group). Total RNA was isolated from medulla, resolved on a gel and probed with an Slc4a8 DNA fragment.

\section{RNA isolation and Northern blot hybridization}

Total cellular RNA was extracted from whole kidney, cortex, medulla, outer medulla and inner medulla according to established methods, quantitated spectrophotometrically, and stored at $-80^{\circ} \mathrm{C}$. Hybridization was performed according to established protocols. The following DNA fragments were used as specific probes for Northern blot hybridization: for Slc4a8, a fragment encoding nucleotides 362-833 from a mouse cDNA (accession number NM_021530); for Pendrin, a fragment corresponding to nucleotides 819-1509 from a mouse cDNA (accession number NM_011867), and for NCC, a DNA fragment spanning the nucleotides 481 to 959 of mouse NCC cDNA (Genebank \# NM_001205311). For renin, a PCR fragment encoding nucleotides 291 to 600 (accession number NM_031192) and for AQP2, a fragment encoding nucleotides 102 to 397 (Accession number: BC128705.1) was used for the epithelial sodium channel, the following subunit specific nucleotide fragments were used: 750-1073 (GenBank accession no. NM_011324) for subunit $\alpha$; 587-902(GenBank accession no. NM_011325) for subunit $\beta$; and nucleotides 621-1012(GenBank accession no. NM_011326) for subunit $\gamma$. Each Northern blot hybridization was performed on three separate samples from three different animals.

\section{Western blotting}

Plasma membrane protein were isolated from kidneys of WT and Slc4a8 KO mice, size-fractionated by SDS/PAGE ( $90 \mu \mathrm{g} /$ lane), and blotted against pendrin or NCC antibodies according to established protocols $[36,37]$. Pendrin antibodies for Western blotting were generous gifts from Dr. Peter Aronson (Yale University). NCC antibodies were purchased from StressMarq Biosciences (British Columbia, Canada). NCC phosphorylated antibodies were purchased from PhosphoSolutions (Aurora, CO). The loading per each lane was assessed by B-actin abundance.

\section{Blood and urine electrolyte analysis}

Mice were housed in metabolic cages and had free access to rodent chow and water. Food intake, water intake, and urine volume were measured daily. Urine was collected under mineral oil. Serum concentrations of $\mathrm{Na}^{+}, \mathrm{K}^{+}, \mathrm{Ca}^{2+}$, and $\mathrm{HCO}_{3}{ }^{-}$were measured in blood with an i-STAT ${ }^{\mathrm{R}}-1$ analyzer and i-STAT EG7+ cartridges (Abbott Laboratories, Abbott Park, IL).

Urine chloride and sodium concentrations were measured using an EasyLyte Plus $\mathrm{Na} / \mathrm{K} / \mathrm{Cl}$ analyzer (Medica, Bedford, MA). Serum concentration of $\mathrm{Na}^{+}, \mathrm{K}^{+}, \mathrm{Ca}^{++}$, and $\mathrm{HCO}_{3}{ }^{-}$were measured using i-STAT ${ }^{\mathrm{R}}-1$ analyzer with i-STAT EG7+ cartridges (Abbott Laboratories, Abbott Park, IL). Urine osmolality was measured with an Advanced Micro Osmometer (Advanced Instruments, Norwood, MA).

\section{Statistical analysis}

Northern hybridization band densities were determined by densitometry with ImageQuaNT software (Molecular Dynamics, Sunnyvale, CA). The results are presented as means \pm SE. Statistical significance between WT and pendrin KO mice was determined by Student's unpaired $t$-test, and $P<0.05$ was considered significant.

\section{Results}

We first examined the expression of Slc4a8 by in situ hybridization. To test the specificity of the antisense probe, we first examined the expression of Slc4a8 in the brain, which is known to have a very high expression level for this transporter [42, 43]. Fig. 1A depicts a sense (left) 


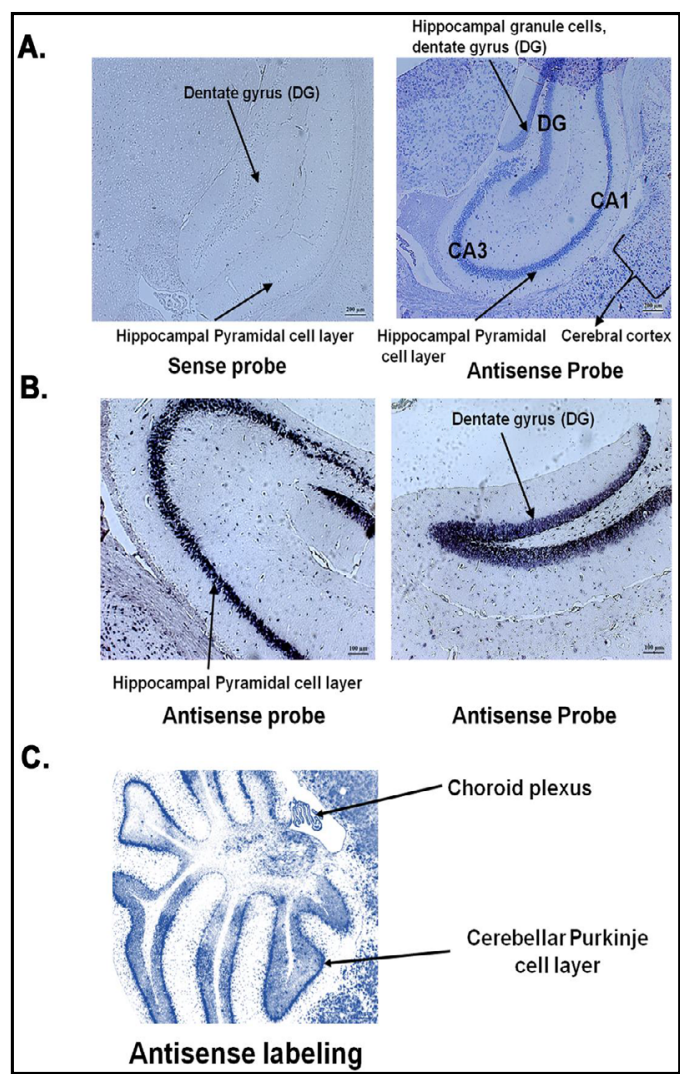

Fig. 1. Expression of Slc4a8 in the brain by in situ hybridization. Fig. 1A depicts sense (left) and antisense (right) labeling in the brain hippocampus and surrounding area. Slc4a8 is specifically detected in the hippocampal pyramidal cell layer and dentate gyrus and in cells in the adjacent cerebral cortex. Fig. 1B (left and right) depicts a high magnification of in situs in the hippocampus and shows specific labeling in hippocampal pyramidal cell layer and dentate gyrus. Fig. $1 \mathrm{C}$ shows specific labeling of Slc4a8 in cerebellar Purkinje cell layer and in the choroid plexus.

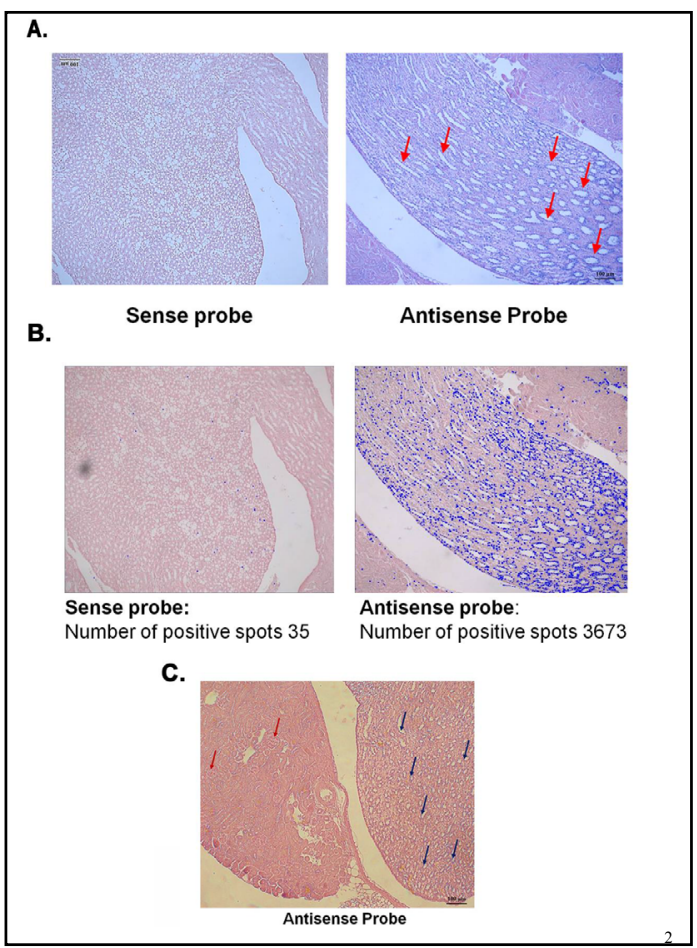

Fig. 2. Expression of Slc4a8 in the kidney by in situ hybridization. Fig. 2A depicts a sense (left) and antisense (right) labeling in the kidney. As shown, Slc4a8 is specifically detected in the inner medulla in segments that resemble medullary collecting ducts (right). Fig. 2B is an analysis of the Fig. 2A using Zeiss Zen 2012 image analysis software. These results show a highly significant Slc4a8 expression level in medullary collecting duct cells. Fig. 2C examines the expression of Slc4a8 in the cortex and medulla by antisense labeling and demonstrates significant expression level in the medulla and its absence in the cortex. Blue arrows point to positive Slc4a8 signal in medulla (right panel). Red arrows indicate the location of glomeruli in the cortex.

and antisense (right) labeling of Slc4a8 probes in the hippocampus and surrounding area. As shown, Slc4a8 is specifically detected in the hippocampal pyramidal cell layer and in dentate gyrus in mouse brain, with cells in the adjacent cerebral cortex also showing specific labeling (right panel). No labeling was detected with the sense probe (left panel), strongly suggesting the specificity of Slc4a8 expression (right panel). Fig. 1B (left and right) depicts a higher magnification of in situ labeling with the antisense probe. Fig. 1C shows specific labeling of Slc4a8 in cerebellar Purkinje cell layer and in the choroid plexus.

Fig. 2A depicts sense (left) and antisense (right) labeling in the kidney. As shown, Slc4a8 is specifically detected in the inner medulla in segments that resemble medullary collecting ducts (right). An analysis of Fig. 2A using Zeiss Zen 2012 image analysis software is shown in Fig. 2B, which shows the specificity of the antisense probe and demonstrates a highly significant Slc4a8 expression level in medullary collecting duct cells.

Fig. 2C examines the expression of Slc4a8 in the cortex and medulla by Slc4a8 antisense labeling and clearly demonstrates significant expression levels in the medulla and its absence 
Fig. 3. Expression of Slc4a8 in various kidney zones by RT-PCR and northern hybridization. Fig. 3A examines the expression of Slc4a8 by semi-quantitative RT-PCR using primers corresponding to the common domain of cDNA encoding Slc4a8 (see Methods). Slc4a8 is detected in outer and inner medulla with no expression in the cortex. The expression of Slc4a8 in the heart is shown for comparison. Fig. 3B is a semi-quantitative RT-PCR using primers corresponding to the $\mathrm{N}$-terminal region of the Slc4a8 variant 2 (absent in variant 1). It shows a similar expression pattern of Slc4a8 in the outer and inner medulla, with no expression in the cortex (Fig. 3B). Fig. 3C is a 40 cycle PCR and shows the absence of Slc4a8 in the cortex. For comparison, expression of OAT1 (Slc22a6) which is detected in both cortex and the whole kidney is shown. Fig. 3D presents a northern hybridization (left) and RT-PCR nephron distribution (right) of Slc4a8 in the brain and kidney. Slc4a8 signal is readily detected in the brain with lower levels in kidney medulla, specifically in the inner medulla, and no expression detected in the cortex. There was no evidence of enhanced expression of Slc4a8 in kidneys of NCC KO or pendrin KO mice (Fig. 3D).
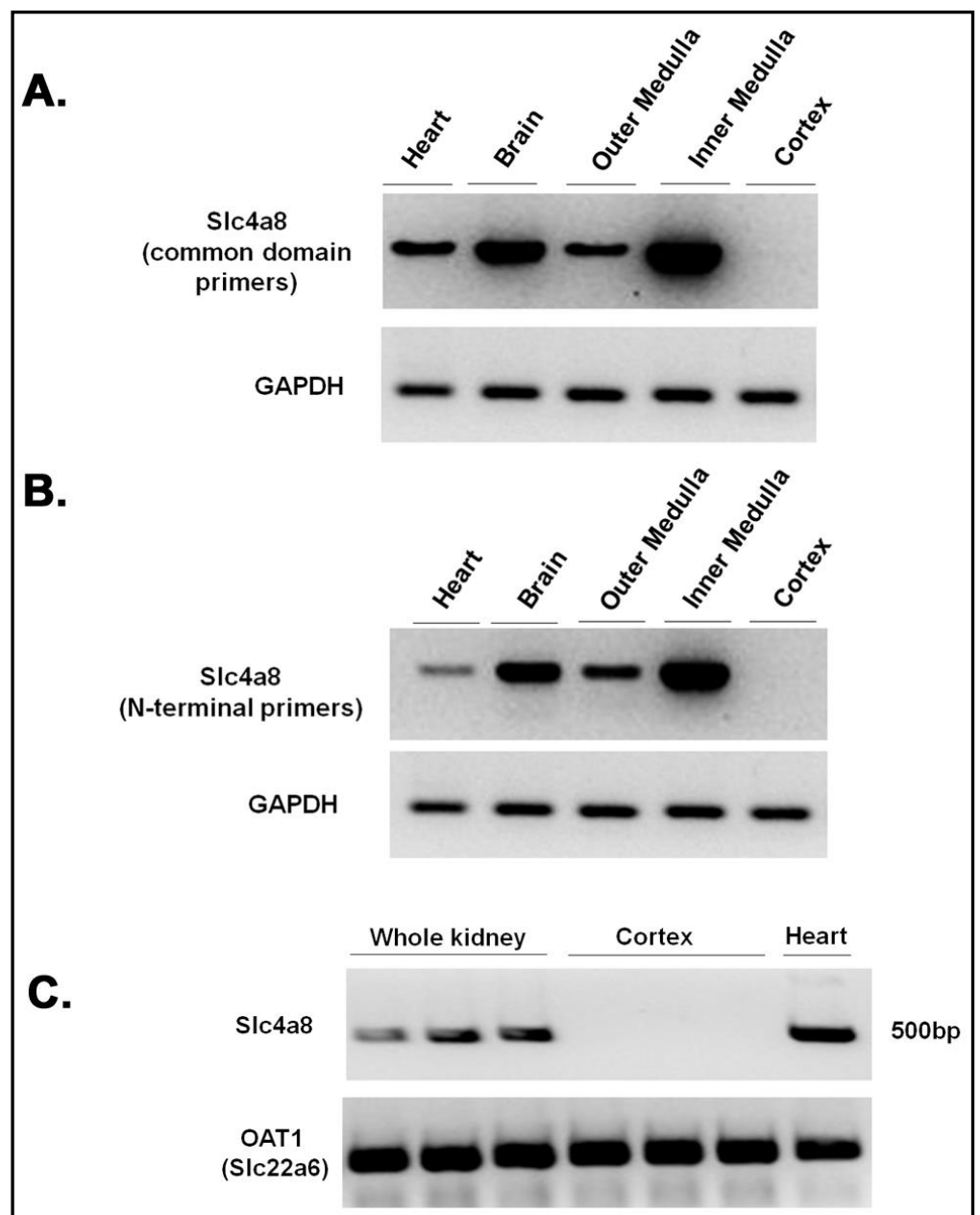

D.

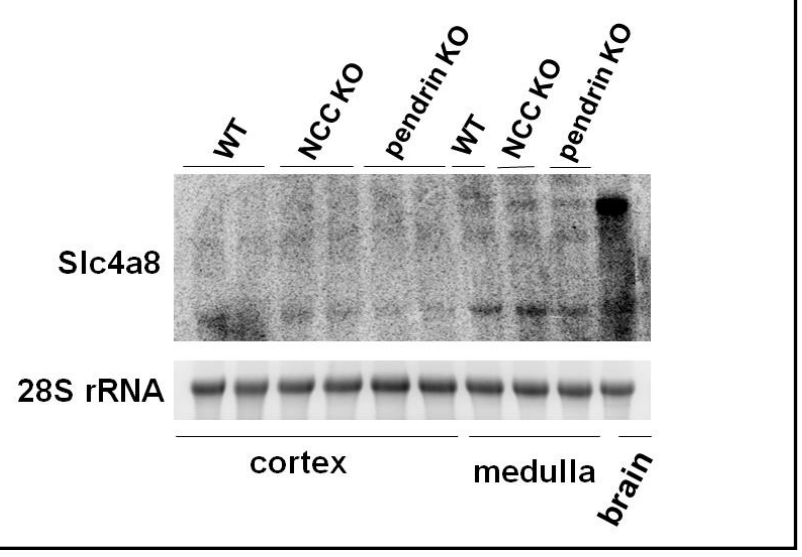

in the cortex. The above results demonstrate that Slc4a8 expression is primarily limited to the medulla, with predominant expression in medullary collecting duct cells.

To further determine the expression of Slc4a8, semi-quantitative RT-PCR was utilized to examine the expression of Slc4a8 in the cortex, outer medulla and inner medulla. As shown in Fig. 3A, using primers corresponding to the common domain of the cDNA encoding Slc4a8 (present in both variants 1 and 2), Slc4a8 exhibits significant expression in outer and inner medulla with no expression in the cortex. The expression of Slc4a8 in the heart [44] is shown for comparison. Using primers corresponding to the N-terminal region of the Slc4a8 variant 2 (absent in variant 1), a similar expression pattern of Slc4a8 was detected in the outer and 


\section{Cellular Physiology and Biochemistry \begin{tabular}{l|l} 
DOl: 10.1159/000494596 & $\begin{array}{l}\text { O 2018 The Author(s). Published by S. Karger AG, Basel } \\
\text { www.karger.com/cpb }\end{array}$
\end{tabular}

Fig. 4. Expression and membrane targeting of Slc4a8 in MDCK cellsFig. $4 \mathrm{~A}$ depicts the expression of GFP in MDCK cells. In the absence of Slc4a8 insert GFP signal is localized to the cytoplasm. Fig. 4B (top panels) illustrates the expression of Slc4a8 in MDCK cells in hypertonic medium. As shown, Slc4a8-GFP is targeted to the plasma membrane when merged images of GFP and phalloidin are acquired (front view or Z-stack image analysis in middle panel). The Slc4a8 is targeted to the basolateral membrane when the side view or Z-line images are acquired (Fig. 4B, bottom panel). Fig. 4C illustrates the expression of Slc4a8 in MDCK cells transfected and maintained in isotonic medium. As indicated, Slc4a8 displays a sub-membrane localization in isotonic medium, when merged images of GFP and phalloidin are acquired (front view or Z-stack image analysis in middle panel). The GFP-tagged Slc4a8 remains in submembrane region when Z-line images were acquired (Fig. $4 \mathrm{C}$, bottom panel). The expression studies using GFP-tagged Slc4a8 construct were repeated 6 times in isotonic or hypertonic medium, which reproducibly showed the targeting of Slc4a8 to the basolateral membrane in hypertonic media.

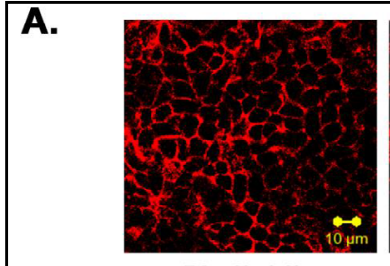

Phalloidin

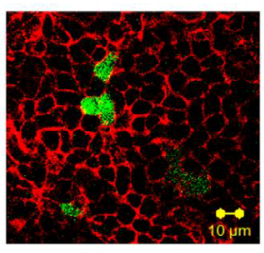

Merged

B. Top panel: Z-stack view

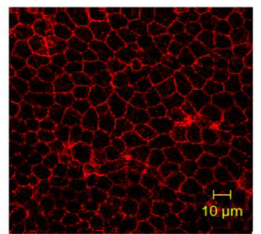

Phalloidin

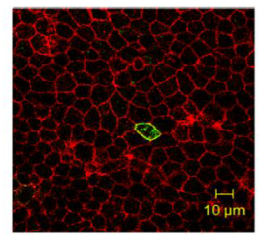

Merged

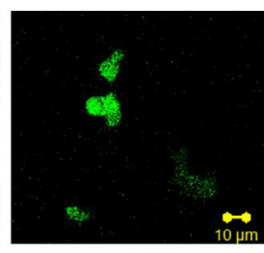

GFP

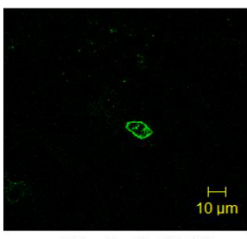

SIc4a8-GFP
Bottom panel: Z-line view

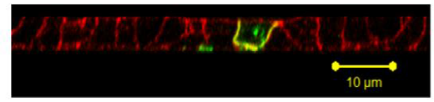

C. Top panel: Z-stack view

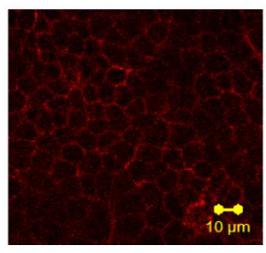

Phalloidin

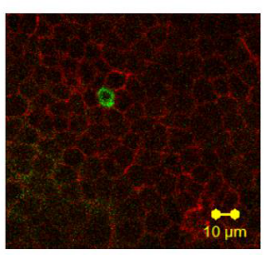

Merged

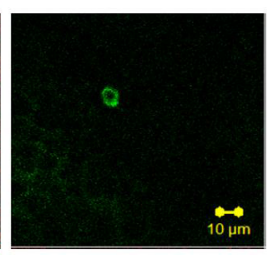

SIc4a8-GFP
Bottom panel: Z-line view

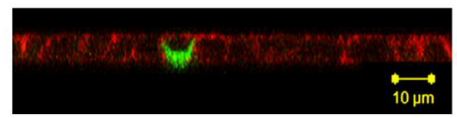

inner medulla, with no expression in the cortex (Fig. 3B). The experiments in Fig. 3A and 3B use the standard 35 cycle PCR approach. Fig. 3C is a 40 cycle PCR and shows the detection of Slc4a8 in the whole kidney, but not in the cortex. For comparison, expression of OAT1 (Slc22a6) is detected in both cortex and the whole kidney. These results indicate that the expression of Slc4a8 in predominantly detected in the kidney medulla and demonstrates its complete absence in the cortex. Fig. 3D is a northern hybridization that shows the readily detected Slc4a8 mRNA signal in the brain with lower levels in kidney medulla and no expression in the cortex. There was no evidence indicating enhanced expression of Slc4a8 in kidneys of NCC KO or pendrin KO mice (Fig. 3D). The mRNA expression levels for Slc4a8, when adjusted for the amount of loading using 28S rRNA levels, were $98+/-7$ and $110+/-6$ $\%$ in Pendrin KO and NCC KO, respectively, vs. control animals ( $p>0.05$ vs. both models, $n=4$ ).

To determine its membrane targeting, Slc4a8 cDNA was epitope-tagged with the GFP and used to transfect the osmotically tolerant kidney MDCK cells. All cells were co-labeled with Alexa Fluor 568 phalloidin (Molecular Probes, Eugene, OR) as a marker of plasma membrane labeling. Cells were switched to either a hypertonic medium or remained in isotonic medium $24 \mathrm{hrs}$ later and fixed $48 \mathrm{~h}$ after transfection. Fig. 4A shows that in the absence of 
Slc4a8 insert the GFP signal is localized to the cytoplasm. Fig. 4B (top panel) demonstrates that Slc4a8-GFP is targeted to the membrane in hypertonic medium when merged images of GFP and phalloidin are acquired (Z-stack image analysis or front view in middle panel). Side view or Z-line image analysis demonstrates that Slc4a8 is targeted to the basolateral membrane (Fig. 4B, bottom panel). Fig. 4C illustrates the expression of Slc4a8 in MDCK cells in isotonic medium. As indicated, Slc4a8 predominantly shows sub-membrane localization in isotonic medium. These results indicate that Slc4a8 can function better in hypertonicity, an environment indigenous to the kidney medulla. The images acquired using a non GFP-tagged construct and a mouse Slc4a8 antibody exhibited a similar expression pattern but were not of the same sharp quality.

To determine the impact of Slc4a8 deletion on the expression of pendrin and NCC, northern and western hybridization studies were performed. Supplementary Fig. S2A depicts northern and western hybridizations of pendrin in Slc4a8 KO mice. As indicate, the mRNA expression level (left panel) and protein abundance (right panel) of pendrin remained unchanged

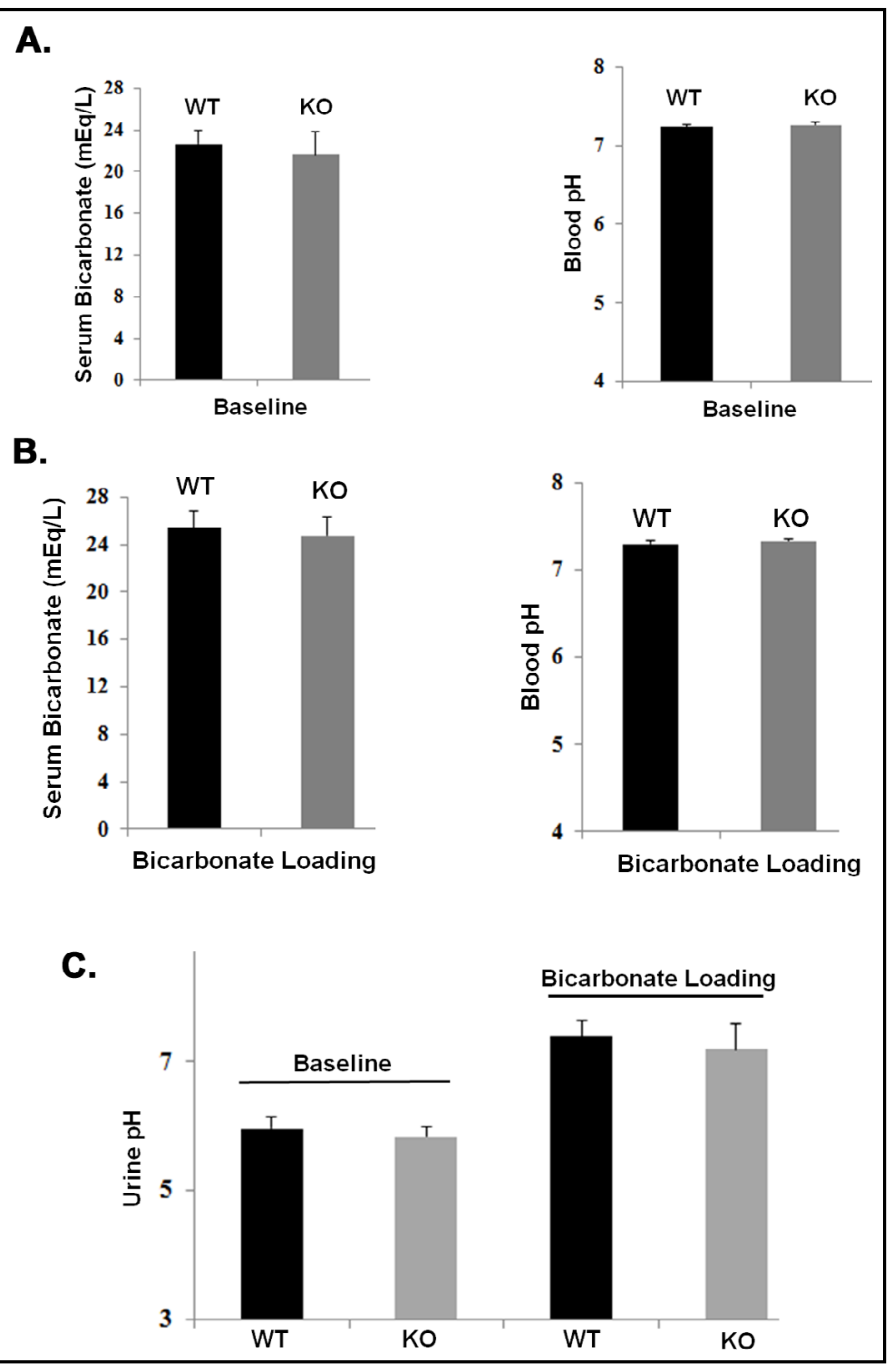

Fig. 5. Effect of bicarbonate loading on systemic acid base status in Slc4a8 KO mice. Fig. 5. A-C. The effect of $\mathrm{HCO}_{3}^{-}$loading (140 $\mathrm{mM} \mathrm{NaHCO}$ added to the drinking water) on acid base and urine parameters in Slc4a8 KO mice was examined. Five (5) animals per each group (WT or KO) were subjected to bicarbonate loading or served as baseline. Urine $\mathrm{pH}$, serum $\mathrm{pH}$ and acid base parameters were comparable in WT and Slc4a8 KO mice following 4 days of bicarbonate loading. Both genotypes showed comparable increases in urine $\mathrm{pH}$ in response to bicarbonate loading. in Slc4a8 KO mice vs. WT mice ( $p>0.05, n=3$ ). Supplementary Fig. S2B shows northern and western hybridizations of NCC (total and phosphorylated) and demonstrates comparable mRNA levels (left panel) and total and phosphorylated NCC abundance (right panel) in Slc4a8 KO mice vs. WT mice ( $p>0.05$, $\mathrm{n}=3$ ).

In the next series of experiments, we examined the role of Slc4a8 in systemic acid base homeostasis and vascular volume regulation by subjecting Slc4a8 KO mice to bicarbonate loading, sodium restriction or furosemide-induced diuresis. In the first series of experiments, we analyzed the effect of $\mathrm{HCO}_{3}^{-}$loading $\left(140 \mathrm{mEq} / \mathrm{l}\right.$ of $\mathrm{NaHCO}_{3}$ added to the drinking water) for 4 days on acid base and urine parameters in Slc4a8 KO mice. Body weights were 


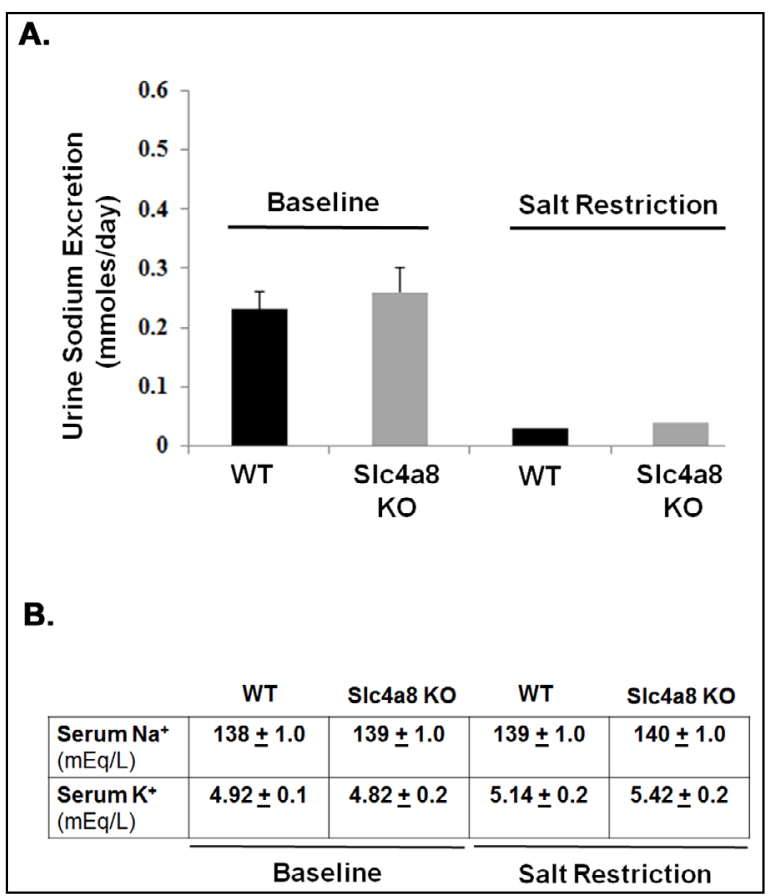

Fig. 6. Effect of salt restriction in Slc4a8 KO mice. The effect of salt restriction $(0.1 \%$ salt in liquid diet $)$ on salt excretion in WT and KO mice was examined. Five (5) animals per each group (WT or KO) were subjected to salt restriction or served as baseline. As indicated in Fig. $6 \mathrm{~A}$, the urine sodium excretion rate dropped significantly and comparably in both genotypes after 6 days of salt restriction. In addition, systemic acid base parameters were comparable in both genotypes (Fig. 6B). Serum $\mathrm{K}^{+}$concentrations remained comparable in WT and $\mathrm{KO}$ mice in response to salt restriction ( $p>0.05, n=5$ per each group).
A.

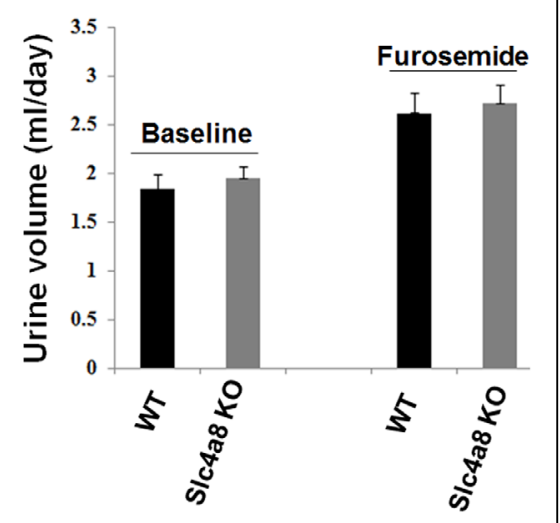

B.

\begin{tabular}{|l|c|c|}
\multicolumn{1}{c}{} & \multicolumn{1}{c|}{ WT } & Slc4a8 KO \\
$\begin{array}{l}\text { Serum } \\
\mathrm{Na}^{+}(\mathrm{mEq} / \mathrm{L})\end{array}$ & $141 \pm 1.0$ & $140 \pm 1.0$ \\
\hline $\begin{array}{l}\text { Serum } \mathrm{K}^{+} \\
(\mathrm{mEq} / \mathrm{L})\end{array}$ & $5.0 \pm 0.1$ & $4.80 \pm 0.1$ \\
\cline { 2 - 3 } & \multicolumn{2}{|c|}{ Furosemide } \\
\hline
\end{tabular}

Fig. 7. Effect of Furosemide-induced diuresis in Slc4a8 KO mice. The magnitude of salt excretion in response to furosemide injection is shown. Five (5) animals per each group (WT or KO) were injected with furosemide or served as baseline. As indicated, salt excretion rates were comparable in WT and Slc4a8 KO mice (Fig. 7). Serum $\mathrm{K}^{+}$concentrations remained comparable in WT and $\mathrm{KO}$ mice in response to furosemide injection ( $\mathrm{p}>0.05, \mathrm{n}=5$ per each group).

comparable in both groups (average body weights in gm were $23.17+/-1.69$ for WT and $25.00+/-1.01$ for KO mice, $\mathrm{p}>0.05$ ). As indicated in Fig. 5A-C, the urine $\mathrm{pH}$, serum $\mathrm{pH}$ and acid base parameters were comparable in WT and Slc4a8 KO mice at baseline and following 4 days of bicarbonate loading. Both genotypes showed comparable increases in urine $\mathrm{pH}$ in response to bicarbonate loading.

The next series of experiments examined the effect of salt restriction on salt excretion in WT and Slc4a8 KO mice. Animals (average body weights in gm were $24.10+/-0.97$ for WT vs. $24.76+/-1.52$ in Slc4a8 KO mice, $p>0.05$ ) were placed in metabolic cages and after acclimation were placed on a low sodium diet ( $0.1 \%$ sodium in liquid diet) for 6 days. As depicted in Fig. 6, the urine sodium excretion rates dropped significantly and comparably in both genotypes. In addition, serum sodium and potassium concentration remained comparable in both genotypes (Fig. 6).

In the next series of experiments, the effect of furosemide injection on urine volume was examined in WT and Slc4a8 KO mice following acclimation in metabolic cages. Average body weights in gm were $26.13+$ /- 1.52 for WT vs. $29.30+/-1.68$ in Slc4a8 KO mice, p>0.05 The magnitude of urine output in response to daily furosemide injection for 3 days was comparable in WT and Slc4a8 KO mice (Fig. 7).

To examine the effect of enhanced tonicity of medulla on the expression of Slc4a8, animals ( 4 per each group) were subjected to water deprivation for $24 \mathrm{hrs}$ (Methods). Medullary RNA 
was isolated and examined for the expression of Slc4a8. The results indicated a $44 \%$ increase in Slc4a8 expression levels in water deprived animals $(\mathrm{p}<0.05, \mathrm{n}=4)$. A representative blot on Slc4a8 expression in water deprivation, using combined medulla of 2 animals, is depicted vs. control animals in Supplementary Fig. S3.

\section{Discussion}

The present studies examine the expression and subcellular localization of Slc4a8 (NDCBE) in the kidney tubules. In situ hybridization studies were first conducted in the brain given the abundant neuronal expression of Slc4a8 based on published immunohistochemical studies $[42,43]$. As indicated in Fig. 1, Slc4a8 is abundantly detected in the hippocampal pyramidal cell layer and in the dentate gyrus. The background (sense labeling) was very minimal (Results). In addition, Slc4a8 is abundantly expressed in the cerebellar Purkinje cell layer and choroid plexus.

The localization pattern of Slc4a8 in situ signal in the kidney is strikingly limited to the medullary collecting duct and sharply drops at the edge of medulla and cortex (Fig. 2). The results of the RT-PCR experiments demonstrate the predominant localization of Slc4a8 in the medullary region with a complete absence of expression in the kidney cortex, including the cortical collecting duct (CCD) (Fig. 3). The expression in the medulla is detected in both the outer and inner sections, and is consistent with the presence of Slc4a8 in the medullary collecting duct, as observed by in situ hybridization.

The expression studies using GFP-tagged or wild type Slc4a8 cDNA in polarized kidney MDCK cells showed that Slc4a8 is localized to the plasma membrane and targeted to the basolateral membrane of osmotically tolerant kidney cells (Fig. 4B). The targeting to the plasma membrane was predominantly observed in hypertonic medium $(400 \mathrm{mOsm})$ (Fig. 4B), whereas Slc4a8 was primarily detected in subapical or the cytoplasmic compartment in isotonic medium (300 m0sm). The side view of GFP-tagged images clearly showed the targeting of Slc4a8 to the basolateral membrane of MDCK cells (Fig. 4B, Bottom panel). Taken together, these results demonstrate that Slc4a8 is localized to the basolateral membrane of medullary collecting duct cells. Whether Slc4a8 localizes to other medullary segments, such as the thin limb of Henle, could not be excluded by our studies.

Slc4a8 was originally named NBC-3, as it was the third NBC isoform to be cloned at the time $[39,40]$. In the original studies, NBC-3 (later designated as Slc4a8 and renamed as NDCBE) was found to co-transport sodium and bicarbonate [40]. In separate studies, Slc4a8 was found to co-transport sodium and bicarbonate in exchange for intracellular chloride and it was renamed as NDCBE [41]. In the original studies, Slc4a8 (NBC-3) was predominantly detected in the kidney medulla $[39,40]$. A study published recently suggested that Slc4a8 is located on the apical membrane of B-intercalated cells in the CCD [45]. However, no confirmatory RT-PCR, in situ hybridization or immunohistochemical staining have been published to support Slc4a8 expression in CCD or B-intercalated cells.

The report on HCTZ sensitivity of salt absorption in perfused CCD in sodium depleted mice was based on a combination of in vivo and in vitro studies [45]. The in vivo component demonstrated enhanced diuresis by HCTZ in NCC KO mice, which lack the known thiazide sensitive NCC [45]. The authors attributed the HCTZ-induced diuresis in NCC KO mice to the inhibition of Slc4a8 (NDCBE), based in part on the inhibition of net salt absorption in perfused CCD tubules by HCTZ but not amiloride [45]. The foremost argument against the HCTZ sensitivity of Slc4a8, however, is the complete resistance to HCTZ inhibition in Oocytes, even at the superphysiologic concentration of $1 \mathrm{mM}$ [45]. Coupled with our expression studies (Results) we would like to propose that Slc4a8 is not expressed in the CCD, including the B-intercalated cells. Further support for the absence of Slc4a8 in the cortical collecting duct was reported in a recent study, which indicated that in single cell isolation of CCD cells (A-IC, B-IC and principal cells) Slc4a8 was not detected [31]. Given the complete absence of Slc4a8 mRNA in the CCD [31], it is highly likely that the signal detected in western blots using 
Slc4a8 antibody on proteins isolated from cortical collecting duct [44] was non specific and did not represent Slc4a8.

A recent study using RNA-seq analysis of kidney cortex in NCC KO vs. WT mice showed significant upregulation of the $\mathrm{Na}^{+} / \mathrm{H}^{+}$exchanger NHE-2 in the DCT of NCC KO mice [ASN abstract: The Cystic Fibrosis Transmembrane Regulator (CFTR) and the $\mathrm{Na}^{+} / \mathrm{H}^{+}$Exchanger NHE-2 Play Important Roles in Compensatory Salt Absorption in Kidneys of $\mathrm{Na}-\mathrm{Cl}$ Cotransport (NCC) Deficient Mice. Soleimani, Xu, Zahedi, and Barone. American Society of Nephrology annual meeting, New Orleans, 2017, unpublished data]. From a thermodynamic point of view, the parallel activation of pendrin and NHE-2 is equivalent to the coupling of an NBC-like pathway with pendrin, in that both pathways lead to enhanced entry of sodium and chloride in an electroneutral manner. It is worth mentioning that the amiloride concentration used in perfused tubules was only $10^{-5} \mathrm{M}$ (or $10 \mu$ mole); whereas, the concentration of HCTZ was 10 times higher $\left(10^{-4} \mathrm{M}\right.$ or $\left.100 \mu \mathrm{mole}\right)$ [44]. Given the relative resistance of NHE-2 to amiloride, we would like to suggest that enhanced electroneutral reabsorption of $\mathrm{Na}^{+}$and $\mathrm{Cl}^{-}$ in NCC KO mice is likely mediated via NHE- 2 and pendrin working in tandem, and a higher concentration of amiloride or an NHE-2 specific inhibitor (such as HOE694) would inhibit the electroneutral salt absorption in the distal nephron of NCC KO mice.

\section{Conclusion}

In conclusion, our studies demonstrate that Slc4a8 is absent in the kidney cortex, including cortical collecting duct, but is primarily expressed on the basolateral membrane of medullary collecting ducts. Slc4a8 KO mice do not exhibit any electrolyte or acid base abnormalities under baseline conditions or in response to bicarbonate loading, salt restriction or furosemide-induced diuresis. Whether Slc4a8 can play a role in intracellular $\mathrm{pH}$ and volume regulation in the medullary collecting duct in pathophysiologic states remains to be determined.

\section{Abbreviations}

PAM (Protospacer adjacent motif).

\section{Acknowledgements}

This work was supported by Merit Review 5 I01 BX001000-06 award from the Department of Veterans Affairs, and funds from the Center on Genetics of Transport and Epithelial Biology at the University of Cincinnati and US Renal Care Inc.

\section{Disclosure Statement}

The authors declare no conflicts of interest.

\section{References}

1 Wang T, Yang CL, Abbiati T, Schultheis PJ, Shull GE, Giebisch G, Aronson PS: Mechanism of proximal tubule bicarbonate absorption in NHE3 null mice. Am J Physiol 1999;277:F298-302.

2 Bobulescu IA, Moe OW: $\mathrm{Na}^{+} / \mathrm{H}^{+}$exchangers in renal regulation of acid-base balance. Semin Nephrol 2006;26:334-344. 


\section{Cellular Physiology Cell Physiol Biochem 2018;50:1361-1375

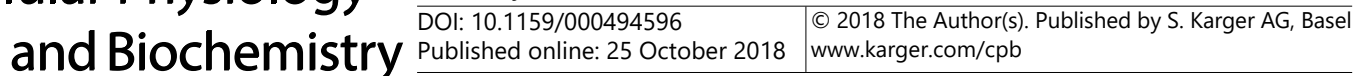 \\ Xu et al.: Slc4a8 in the Kidney}

- 3 McDonough AA, Nguyen MT: Maintaining balance under pressure: Integrated regulation of renal transporters during hypertension. Hypertension 2015;66:450-455.

4 Bailey MA, Giebisch G, Abbiati T, Aronson PS, Gawenis LR, Shull GE, Wang T: NHE2-mediated bicarbonate reabsorption in the distal tubule of NHE3 null mice. J Physiol 2004;561:765-775.

-5 Grimm PR, Welling PA: $\alpha$-Ketoglutarate drives electroneutral $\mathrm{NaCl}$ reabsorption in intercalated cells by activating a G-protein coupled receptor, Oxgr1. Curr Opin Nephrol Hypertens 2017;26:426-433.

6 Romero MF, Chen AP, Parker MD, Boron WF: The SLC4 family of bicarbonate $\left(\mathrm{HCO}_{3}{ }^{-}\right)$transporters. Mol Aspects Med 2013;34:159-182.

7 Soleimani M: SLC26 Cl-/HCO3- exchangers in the kidney: roles in health and disease. Kidney Int 2013;84:657-666. Kurtz I: Molecular mechanisms and regulation of urinary acidification. Compr Physiol 2014;4:1737-1774. Purkerson JM, Schwartz GJ: The role of carbonic anhydrases in renal physiology. Kidney Int 2007;71:103115.

10 Arroyo JP, Kahle KT, Gamba G: The SLC12 family of electroneutral cation-coupled chloride cotransporters. Mol Aspects Med 2013;34:288-298.

11 Delpire E, Kaplan MR, Plotkin MD, Hebert SC: The Na-(K)-Cl cotransporter family in the mammalian kidney: molecular identification and function(s). Nephrol Dial Transplant 1996;11:1967-1973.

12 Kim GH, Masilamani S, Turner R, Mitchell C, Wade JB, Knepper MA: The thiazide-sensitive Na-Cl cotransporter is an aldosterone-induced protein. Proc Natl Acad Sci USA 1998;95:14552-14557.

13 Rozansky DJ, Cornwall T, Subramanya AR, Rogers S, Yang YF, David LL, Zhu X, Yang CL, Ellison DH: Aldosterone mediates activation of the thiazide-sensitive Na-Cl cotransporter through an SGK1 and WNK4 signaling pathway. J Clin Invest 2009;119:2601-2612.

14 Hoorn EJ, Walsh SB, McCormick JA, Fürstenberg A, Yang CL, Roeschel T, Paliege A, Howie AJ, Conley J, Bachmann S, Unwin RJ, Ellison DH: The calcineurin inhibitor tacrolimus activates the renal sodium chloride cotransporter to cause hypertension. Nat Med 2011;17:1304-1309.

15 Soleimani M, Greeley T, Petrovic S, Wang Z, Amlal H, Kopp P, Burnham CE: Pendrin: an apical Cl $/ \mathrm{OH}^{-} / \mathrm{HCO}_{3}^{-}$ exchanger in the kidney cortex. Am J Physiol Renal Physiol 2001;280:F356-364.

-16 Royaux IE, Wall SM, Karniski LP, Everett LA, Suzuki K, Knepper MA, Green ED: Pendrin, encoded by the Pendred syndrome gene, resides in the apical region of renal intercalated cells and mediates bicarbonate secretion. Proc Natl Acad Sci USA 2001;98:4221-4226.

17 Roy A, Al-bataineh MM, Pastor-Soler NM: Collecting duct intercalated cell function and regulation. Clin J Am Soc Nephrol 2015;10:305-324.

18 Wagner CA, Mohebbi N, Capasso G, Geibel JP: The anion exchanger pendrin (SLC26A4) and renal acid-base homeostasis. Cell Physiol Biochem 2011;28:497-504.

19 Wall SM, Hassell KA, Royaux IE, Green ED, Chang JY, Shipley GL, Verlander JW: Localization of pendrin in mouse kidney. Am J Physiol Renal Physiol 2003;284:F229-241.

20 Vallet M, Picard N, Loffing-Cueni D, Fysekidis M, Bloch-Faure M, Deschênes G, Breton S, Meneton P, Loffing J, Aronson PS, Chambrey R, Eladari D: Pendrin regulation in mouse kidney primarily is chloride-dependent. J Am Soc Nephrol 2006;17:2153-2163.

-21 Weiner ID, Hamm LL: Molecular mechanisms of renal ammonia transport. Annu Rev Physiol 2007;69:317340.

-22 Caner T, Abdulnour-Nakhoul S, Brown K, Islam MT, Hamm LL, Nakhoul NL: Mechanisms of ammonia and ammonium transport by rhesus-associated glycoproteins. Am J Physiol Cell Physiol 2015;309:C747-758.

-23 Alper SL, Natale J, Gluck S, Lodish HF, Brown D: Subtypes of intercalated cells in rat kidney collecting duct defined by antibodies against erythroid band 3 and renal vacuolar H+-ATPase. Proc Natl Acad Sci USA 1989;86:5429-5433.

24 Soundararajan R, Pearce D, Hughey RP, Kleyman TR: Role of epithelial sodium channels and their regulators in hypertension. J Biol Chem 2010;285:30363-30369.

25 Brooks HL, Sorensen AM, Terris J, Schultheis PJ, Lorenz JN, Shull GE, Knepper MA: Profiling of renal tubule Na+ transporter abundances in NHE3 and NCC null mice using targeted proteomics. J Physiol 2001;530:359-366.

26 Satlin LM, Carattino MD, Liu W, Kleyman TR: Regulation of cation transport in the distal nephron by mechanical forces. Am J Physiol Renal Physiol 2006;1:F923-931. 


\section{Cellular Physiology Cell Physiol Biochem 2018;50:1361-1375 and Biochemistry \begin{tabular}{l|l} 
DOl: 10.1159/000494596 & $\begin{array}{l}\text { O 2018 The Author(s). Published by S. Karger AG, Basel } \\
\text { www.karger.com/cpb }\end{array}$
\end{tabular}

-27 Svenningsen P, Andersen H, Nielsen LH, Jensen BL: Urinary serine proteases and activation of ENaC in kidney--implications for physiological renal salt handling and hypertensive disorders with albuminuria. Pflugers Arch 2015;467:531-542.

-28 Pavlov TS, Staruschenko A: Involvement of ENaC in the development of salt-sensitive hypertension. Am J Physiol Renal Physiol 2017;313:F135-140.

-29 Verlander JW, Hassell KA, Royaux IE, Glapion DM, Wang ME, Everett LA, Green ED, Wall SM: Deoxycorticosterone upregulates PDS (Slc26a4) in mouse kidney: role of pendrin in mineralocorticoidinduced hypertension. Hypertension 2003;42:356-362.

-30 Kim YH, Kwon TH, Frische S, Kim J, Tisher CC, Madsen KM, Nielsen S: Immunocytochemical localization of pendrin in intercalated cell subtypes in rat and mouse kidney. Am J Physiol Renal Physiol 2002;283:F744754.

31 Chen L, Lee JW, Chou CL, Nair AV, Battistone MA, Păunescu TG, Merkulova M, Breton S, Verlander JW, Wall SM, Brown D, Burg MB, Knepper MA: Transcriptomes of major renal collecting duct cell types in mouse identified by single-cell RNA-seq. Proc Natl Acad Sci USA 2017;114:E9989-9998.

-32 Xu N, Hirohama D, Ishizawa K, Chang WX, Shimosawa T, Fujita T, Uchida S, Shibata S: Hypokalemia and Pendrin Induction by Aldosterone. Hypertension 2017;69:855-862.

33 Wall SM, Kim YH, Stanley L, Glapion DM, Everett LA, Green ED, Verlander JW: NaCl restriction upregulates renal Slc26a4 through subcellular redistribution: role in $\mathrm{Cl}^{-}$conservation. Hypertension 2004;44:982-987.

-34 Amlal H, Petrovic S, Xu J, Wang Z, Sun X, Barone S, Soleimani M: Deletion of the anion exchanger Slc26a4 (pendrin) decreases apical $\mathrm{Cl}(-) / \mathrm{HCO}(-)$ exchanger activity and impairs bicarbonate secretion in kidney collecting duct. Am J Physiol Cell Physiol 2010;299:C33-41.

-35 Soleimani M, Barone S, Xu J, Shull GE, Siddiqui F, Zahedi K, Amlal H: Double knockout of pendrin and Na-Cl cotransporter (NCC) causes severe salt wasting, volume depletion, and renal failure. Proc Natl Acad Sci USA 2012;109:13368-13373.

-36 Zahedi K, Barone S, Xu J, Soleimani M: Potentiation of the effect of thiazide derivatives by carbonic anhydrase inhibitors: molecular mechanisms and potential clinical implications. PLoS One 2013;8:e79327.

37 Patel-Chamberlin M, Varasteh Kia M, Xu J, Barone S, Zahedi K, Soleimani M: The Role of Epithelial Sodium Channel ENaC and the Apical Cl-/HCO3- Exchanger Pendrin in Compensatory Salt Reabsorption in the Setting of Na-Cl Cotransporter (NCC) Inactivation. PLoS One 2016;11:e0150918.

-38 Alshahrani S, Soleimani M: Ablation of the Cl-/HCO3- Exchanger Pendrin Enhances HydrochlorothiazideInduced Diuresis. Kidney Blood Press Res 2017;42:444-455.

-39 Amlal H, Burnham CE, Soleimani M: Characterization of Na+/HCO-3 cotransporter isoform NBC-3. Am J Physiol 1999;276:F903-913.

40 Wang Z, Conforti L, Petrovic S, Amlal H, Burnham CE, Soleimani M: Mouse Na+: HCO3- cotransporter isoform NBC-3 (kNBC-3): cloning, expression, and renal distribution. Kidney Int 2001;59:1405-1414.

41 Grichtchenko II, Choi I, Zhong X, Bray-Ward P, Russell JM, Boron WF: Cloning, characterization, and chromosomal mapping of a human electroneutral $\mathrm{Na}(+)$-driven $\mathrm{Cl}-\mathrm{HCO} 3$ exchanger. J Biol Chem 2001;276:8358-8363.

42 Chen LM, Kelly ML, Parker MD, Bouyer P, Gill HS, Felie JM, Davis BA, Boron WF: Expression and localization of Na-driven Cl-HCO(3)(-) exchanger (SLC4A8) in rodent CNS. Neuroscience 2008;153:162-174.

$\checkmark 43$ Ruffin VA, Salameh AI, Boron WF, Parker MD: Intracellular pH regulation by acid-base transporters in mammalian neurons. Front Physiol 2014;5:43.

44 Parker MD, Bouyer P, Daly CM, Boron WF: Cloning and characterization of novel human SLC4A8 gene products encoding $\mathrm{Na}+$-driven $\mathrm{Cl}$-/HCO3(-) exchanger variants NDCBE-A, -C, and -D. Physiol Genomics 2008;34:265-276.

45 Leviel F, Hübner CA, Houillier P, Morla L, El Moghrabi S, Brideau G, Hassan H, Parker MD, Kurth I, Kougioumtzes A, Sinning A, Pech V, Riemondy KA, Miller RL, Hummler E, Shull GE, Aronson PS, Doucet A, Wall SM, Chambrey R, et al.: The Na+-dependent chloride-bicarbonate exchanger SLC4A8 mediates an electroneutral $\mathrm{Na}+$ reabsorption process in the renal cortical collecting ducts of mice. J Clin Invest 2010;120:1627-1635.

-46 Sinning A, Radionov N, Trepiccione F, López-Cayuqueo KI, Jayat M, Baron S, Cornière N, Alexander RT, Hadchouel J, Eladari D, Hübner CA, Chambrey R: Double Knockout of the Na+-Driven Cl-/HCO3- Exchanger and $\mathrm{Na}+/ \mathrm{Cl}$ - Cotransporter Induces Hypokalemia and Volume Depletion. J Am Soc Nephrol 2017;28:130139. 
Cellular Physiology Cell Physiol Biochem 2018;50:1361-1375

\begin{tabular}{ll|l} 
and Biochemistry & $\begin{array}{l}\text { DOI: 10.1159/000494596 } \\
\text { Published onlIne: } 25 \text { October } 2018\end{array}$ & $\begin{array}{l}\text { @ 2018 The Author(s). Published by S. Karger AG, Basel } \\
\text { www.karger.com/cpb }\end{array}$ \\
\hline
\end{tabular}

Xu et al.: Slc4a8 in the Kidney

47 Li HC, Worrell RT, Matthews JB, Husseinzadeh H, Neumeier L, Petrovic S, Conforti L, Soleimani M: Identification of a carboxyl-terminal motif essential for the targeting of Na+-HCO-3 cotransporter NBC1 to the basolateral membrane. J Biol Chem 2004;279:43190-43217.

48 Xu J, Worrell RT, Li HC, Barone SL, Petrovic S, Amlal H, Soleimani M: Chloride/bicarbonate exchanger SLC26A7 is localized in endosomes in medullary collecting duct cells and is targeted to the basolateral membrane in hypertonicity and potassium depletion. J Am Soc Nephrol 2006;17:956-967.

49 Barone S, Amlal H, Xu J, Kujala M, Kere J, Petrovic S, Soleimani M: Differential regulation of basolateral Cl-/HCO3- exchangers SLC26A7 and AE1 in kidney outer medullary collecting duct. J Am Soc Nephrol 2004;15:2002-2011. 